\title{
A Randomized Comparative Study of TEP with and without Mesh Fixation Device
}

\author{
Ravi Ranjan ${ }^{1}$, Vivek Srivastava ${ }^{2 *}$ and Mumtaz A. Ansari ${ }^{3}$ \\ 1 Junior Resident, Department of General Surgery, Institute of Medical Sciences, Banaras Hindu \\ University, Varanasi - 221005, Uttar Pradesh, India \\ ${ }^{2}$ Associate Professor, Department of General Surgery, Institute of Medical Sciences, Banaras \\ Hindu University, Varanasi - 221005, Uttar Pradesh, India; vivekims97@gmail.com \\ ${ }^{3}$ Professor, Department of General Surgery, Institute of Medical Sciences, Banaras Hindu \\ University, Varanasi - 221005, Uttar Pradesh, India
}

\begin{abstract}
This study aims to compare the outcome of Total Extra Peritoneal (TEP) hernia repair procedure with or without using mesh fixation device. A total of 60 patients with clinically diagnosed, non-recurrent, uncomplicated symptomatic inguinal hernias were randomized into two groups: 30 patients to TEP with fixation of mesh and 30 patients to TEP without fixation of mesh. Visual Analogue Scale (VAS) was assessed during the immediate postoperative period at 1, 6, and 24 hrs and at 1 week and at 3 months of follow-up. We analyzed demographic profile, symptoms and examination findings, operative variables, postoperative complications, stay in hospital and cost of treatment. The mean ages were $45.8 \pm 13.74$ years for the non-mesh fixed group and $55.47 \pm 16.74$ years for the mesh fixed group. The patients in the mesh fixed group were significantly older than non-fixed group ( $\mathrm{p}=0.017)$. After 1,6 and 24 hours of surgery, the mean VAS score was significantly low in non-fixed group ( $\mathrm{p}=0.003, \mathrm{p}=0.033$ and $\mathrm{p}=0.047$ respectively). After 1 week and 3 months of surgery, the VAS score was comparable in both the groups $(\mathrm{p}=0.126, \mathrm{p}=0.183)$. The mean duration of surgery in both the groups were comparable $(\mathrm{p}=0.258)$. The mean analgesic use in mesh fixed group was $1.42 \pm 0.62$ and in non-fixed group was $1.18 \pm 0.57$ which was comparable $(\mathrm{p}=0.124)$. Prior to discharge, the mean analgesic use was significantly less in non-fixed group $(\mathrm{p}=0.003)$. On comparing complications, urinary retention was significantly less in non-fixed group $(\mathrm{p}=0.0 .028)$. The mean length of hospital stay and mean time to return to normal activities were significantly less in non-fixed group $(\mathrm{p}=0.026$ and $\mathrm{p}<0.001$ respectively). In non-fixed group, the cost of treatment was significantly low $(\mathrm{p}<0.001)$. TEP repair is feasible and safe without mesh fixation device.
\end{abstract}

Keywords: Inguinal Hernia, Mesh Fixation, Total Extra Peritoneal (TEP) Repair

\section{Introduction}

The most common type of hernia is the inguinal hernia. The incidence in males is about $2.5 \%$ and in females is about 2\%. Repair of inguinal hernia significantly contributes to the workload of the general surgeon. Mesh repair has been the gold standard in providing a permanent reinforcement by causing fibrosis in tissue.
In absence of mesh tissue approximation itself provides the tissue strength along with the post-operative fibrosis resulting from surgical trauma.

Total Extra Peritoneal (TEP) repair of inguinal hernias is rapidly becoming an established procedure. The main advantages of TEP over open hernia repair are decreased postoperative pain and less morbidity ${ }^{1-5}$. It is now recommended that laparoscopic hernia repair be the

${ }^{*}$ Author for correspondence 
method of choice for bilateral and recurrent inguinal hernias ${ }^{6}$.

This technique consists of placing polypropylene mesh in pre-peritoneal space. The mesh fixing issue in TEP inguinal hernia repair remains unresolved. The mesh was traditionally fixed by surgeons using laparoscopic stapling device, tacks, suturing techniques and recently adhesives. Mesh fixation is done to prevent mesh migration leading to recurrence but different studies have shown that cases without mesh fixation are not associated with any increased risk of hernia recurrence. Fixing the mesh however not only increases the cost and duration of the procedure but can also cause complications such as postoperative pain ${ }^{7}$.

TEP's disadvantages include the need for General Anesthesia (GA), the need to fix the mesh, the development of seromas, and the difficult curve to learn. Fixing the mesh with metal staples will lead to new post-operative groin pain, apart from increasing the costs ${ }^{1,8,9}$, which even in a small percentage of patients can become chronic ${ }^{10}$. This resulted in several studies showing that non-fixing the mesh is safe, less expensive and does not result in an increased risk of hernia recurrence compared to traditional open hernia repair ${ }^{7,11}$.

However, in this study we compared the outcome of TEP hernia repair procedure with and without using mesh fixation device. We analyzed demographic profile, symptoms and examination findings, operative variables, postoperative complications, stay in hospital and cost of treatment.

\section{Methods}

This study was conducted in the Department of General Surgery, Institute of Medical Science, Banaras Hindu University, Varanasi from September 2017 to May 2019 were included in the study. This is a prospective comparative study which was done after obtaining ethical approval from the ethical committee of the institute. Sixty patients diagnosed clinically with non-recurrent, uncomplicated symptomatic inguinal hernias were randomized into two groups: 30 patients to TEP with fixation of mesh (group I) and 30 patients to TEP without fixation of mesh (group II) using computer generated random number table. Both procedures were performed under general anesthesia.

Exclusion criteria were patients with significant medical comorbidities, like hypertension, bronchial asthma, diabetes, or any other systemic disease likely to delay the recovery of the patient, American College of Anesthesiology Grade III or more, uncorrectable coagulopathy and suspected intra-abdominal or pelvic malignancy. Patients presenting with complicated hernia, recurrent hernia or previous abdominal surgery were also excluded from the study. After enrolment in the study the patients were randomly allocated to Mesh Fixed group or Mesh not fixed group. In Mesh Fixed group the polypropylene mesh used was fixed using absorbable tacks. In the medial part two tacks were placed each at the pubic bone and rectus abdominus muscle. In the lateral part mesh was fixed with one tack in the upper part while the lower one was left unfixed. The Mesh not fixed group had only the mesh spread over the dissected peritoneum and the pneumoperitoneum was gradually removed under vision. The group was assigned by using computer generated random number table.

A dose of prophylactic antibiotic was given 30 minutes before surgery. Post operatively the patients were kept nil by mouth and advised complete bed rest till the effect of anesthesia is completely worn out, till then they were given supportive maintenance intravenous fluids. Patients were advised and encouraged to ambulate and start their activities of daily life as early as possible. Prophylactic antibiotics were given for duration of 5 to 8 days, of which parenteral antibiotics were given for at first 48 hours. Analgesics were given at 12 hour interval for a period of 3 to 5 days, shifted on to oral tablets as early as possible.

Standard surgical procedure for TEP repair involved a transverse incision 1 inch below the level of the umbilicus slightly lateral to the side of the hernia for placement of a $10-\mathrm{mm}$ trocar through which creation of the extra peritoneal space was done. This port was also used for 30 degree $10 \mathrm{~mm}$ telescope and two 5-mm trocars were subsequently placed in midline under direct vision. After necessary dissection was done by the standard method, a $12 \times 15 \mathrm{~cm}$ knit polypropylene mesh was introduced. Depending on the group the mesh was fixed or left unfixed. Bupivacaine $0.5 \%$ was used for TEP repairs titrated to body weight. For TEP repairs infiltration around the port sites and into the preperitoneal space was employed. The infra-umbilical fascial defect was closed with No. 1 polyglactin suture and both $5 \mathrm{~mm}$ port sheath were not closed. As a standard protocol drain was not placed.

The postoperative pain was measured using Visual Analogue Scale (VAS) where a score ranged from 0 representing no pain to a score of 10 corresponding to 
the worst pain. VAS was assessed during the immediate postoperative period at 1,6 , and $24 \mathrm{hrs}$ and at 1 week and at 3 months of follow-up.

A restructured proforma was used to enter all the data. In case the patients were unable to attend the follow-up clinic, the proforma were completed by telephonic conversation. Data was recorded and analyzed includes demographic profile, symptoms and examination findings, operative variables, complications, hospital stay and cost of treatment. Statistical evaluation and final assessment of result after follow up was done.

Statistical analysis was done using SPSS software version (23.0) for windows (IBM Inc., Chicago, USA). For categorical variables Chi square test and Fisher's exact test were used. On comparing two groups of mean Student's $t$ test was applied. P value $<0.05$ is considered as statistically significant.

\section{Results}

The mean ages were $45.8 \pm 13.74$ years for the nonmesh fixed group and $55.47 \pm 16.74$ years for the mesh fixed group. The patients in the mesh fixed group were significantly older than the patients in the non-fixed group ( $\mathrm{p}=0.017$ ). In both the groups, majority of cases have duration of symptoms $>6$ months. The comparison of symptoms, associated symptoms and clinical examination findings in mesh fixed and non-fixed group is shown in (Table 1). The mean operative time in mesh fixed group was $71.0 \pm 16.18$ minutes and in non fixed group was $65.74 \pm 19.41$ minutes. Both the groups took almost equal time which was statistically insignificant $(\mathrm{p}=0.258)$.

On comparing pain intensity using VAS score in mesh fixed and non-fixed group. After 1, 6 and 24 hours of surgery, the mean VAS score was significantly low in nonfixed group ( $\mathrm{p}=0.003, \mathrm{p}=0.033$ and $\mathrm{p}=0.047$ ). After 1 week and 3 months of surgery, the VAS score was almost equal in both the groups which showed statistically insignificant result ( $\mathrm{p}=0.126, \mathrm{p}=0.183$ ) (Table 2 and Figure 1).

In first hour after surgery, the mean analgesic use in mesh fixed group was $1.42 \pm 0.62$ and in non-fixed group was $1.18 \pm 0.57$ which was comparable $(\mathrm{p}=0.124)$. In prior to discharge, the mean analgesic use in non-fixed group was significantly less as compared to mesh fixed group $(\mathrm{p}=0.003)$. On comparing complications (seroma and urinary retention) between mesh fixed and non-fixed group, seroma was present in $2(6.7 \%)$ patients in mesh fixed group and 5 (16.7) patients in non-fixed group.
Table 1. Comparison of symptoms, associated symptoms and clinical examination findings

\begin{tabular}{|c|c|c|c|c|c|}
\hline & \multicolumn{2}{|c|}{$\begin{array}{l}\text { Mesh fixed } \\
\text { group } \\
(\mathbf{n}=\mathbf{3 0})\end{array}$} & \multicolumn{2}{|c|}{$\begin{array}{l}\text { Mesh non } \\
\text { fixed group } \\
\quad(n=30)\end{array}$} & \multirow[t]{2}{*}{ P-value } \\
\hline & No. & $\%$ & No. & $\%$ & \\
\hline \multicolumn{6}{|c|}{ Symptoms } \\
\hline Swelling in groin & 18 & 60.0 & 19 & 63.33 & 0.790 \\
\hline $\begin{array}{l}\text { Swelling in groin } \\
\text { extending to } \\
\text { scrotum }\end{array}$ & 3 & 10.0 & 2 & 6.66 & 0.640 \\
\hline Pain in abdomen & 4 & 13.33 & 3 & 10.0 & 0.687 \\
\hline \multicolumn{6}{|c|}{ Associated symptoms } \\
\hline Chronic Cough & 8 & 26.67 & 7 & 23.33 & 0.765 \\
\hline Constipation & 6 & 20.00 & 8 & 26.67 & 0.541 \\
\hline Lower UTI & 1 & 3.33 & 2 & 6.67 & 0.553 \\
\hline $\begin{array}{l}\text { Previous } \\
\text { operation }\end{array}$ & 9 & 30.00 & 11 & 36.67 & 0.583 \\
\hline Others & 1 & 3.33 & 3 & 10.00 & 0.302 \\
\hline \multicolumn{6}{|c|}{ Clinical examination findings } \\
\hline $\begin{array}{l}\text { Any visible } \\
\text { swelling }\end{array}$ & 18 & 60.00 & 19 & 63.33 & 0.790 \\
\hline $\begin{array}{l}\text { Expansile cough } \\
\text { impulse }\end{array}$ & 30 & 100.00 & 30 & 100.00 & - \\
\hline Tenderness & 1 & 3.33 & 2 & 6.67 & 0.553 \\
\hline $\begin{array}{l}\text { Get above the } \\
\text { swelling }\end{array}$ & 3 & 10.00 & 5 & 16.67 & 0.447 \\
\hline Reducibility & 30 & 100.00 & 30 & 100.00 & - \\
\hline $\begin{array}{l}\text { Deep ring } \\
\text { occlusion test }\end{array}$ & 21 & 70.00 & 23 & 76.67 & 0.559 \\
\hline
\end{tabular}

Table 2. Comparison of Mean VAS score between mesh fixed group and non-fixed group

\begin{tabular}{|l|l|l|l|}
\hline $\begin{array}{l}\text { VAS } \\
\text { score after } \\
\text { surgery }\end{array}$ & $\begin{array}{l}\text { Mesh fixed } \\
\text { group }(\mathbf{n = 3 0})\end{array}$ & $\begin{array}{l}\text { Mesh non } \\
\text { fixed group } \\
(\mathbf{n}=30)\end{array}$ & p-value \\
\hline 1 hour & $2.0 \pm 0.54$ & $1.45 \pm 0.82$ & 0.003 \\
\hline 6 hour & $1.95 \pm 1.11$ & $1.40 \pm 0.82$ & 0.033 \\
\hline 24 hour & $1.54 \pm 1.36$ & $0.98 \pm 0.66$ & 0.047 \\
\hline 1 week & $0.71 \pm 0.48$ & $0.52 \pm 0.47$ & 0.126 \\
\hline 3 month & $0.63 \pm 0.58$ & $0.44 \pm 0.51$ & 0.183 \\
\hline
\end{tabular}




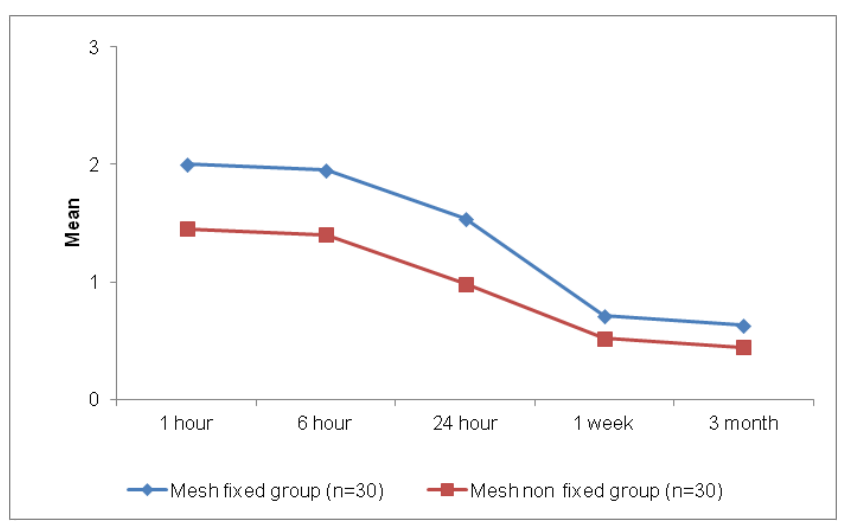

Figure 1. Comparison of Mean VAS score between mesh fixed group and non-fixed group.

Seroma was high in non-fixed group but it was statistically insignificant $(\mathrm{p}=0.228)$. Urinary retention was present in $10(33.33 \%)$ patients in mesh fixed group and $3(10.0 \%)$ patients in non-fixed group. It was significantly high in mesh fixed group as compared to non-fixed group $(\mathrm{p}=0.0 .028)$ (Table 3).

Table 3. Comparison of postoperative analgesic use and complications between mesh fixed and non-fixed group

\begin{tabular}{|l|c|c|c|}
\hline & $\begin{array}{c}\text { Mesh fixed } \\
\text { group } \\
(\mathbf{n}=\mathbf{3 0})\end{array}$ & $\begin{array}{c}\text { Mesh non } \\
\text { fixed group } \\
(\mathbf{n}=\mathbf{3 0})\end{array}$ & p-value \\
\hline Analgesic use (Mean \pm SD) & $1.18 \pm 0.57$ & 0.124 \\
\hline $\begin{array}{l}\text { 1st hour after } \\
\text { surgery }\end{array}$ & $1.42 \pm 0.62$ & $2.32 \pm 1.81$ & 0.003 \\
\hline Prior to discharge & $4.63 \pm 3.74$ & & 0.228 \\
\hline Complications (No, \%) & $2(6.7)$ & $5(16.7)$ & 0.028 \\
\hline Seroma & $10(33.33)$ & $3(10.0)$ & \\
\hline Urinary retention & \multicolumn{2}{|l|}{} \\
\hline
\end{tabular}

On comparing postoperative follow up data between mesh fixed group and non-fixed group, the mean length of hospital stay in was significantly more in mesh fixed group as compared to non fixed group $(\mathrm{p}=0.026)$. The mean time to return to normal activities was $9.45 \pm 3.22$ days in mesh fixed group and $6.45 \pm 2.14$ days in non-fixed group, which showed in non-fixed group had early return to normal activities as compared to mesh fixed group $(\mathrm{p}<0.001)$. In mesh fixed group, the cost of treatment was $30500.00 \pm 4500.00$ rupees and in non-fixed group it was $12000.00 \pm 3800.00$ rupees which showed the cost of treatment was significantly low in non-fixed group as compared to mesh fixed group $(\mathrm{p}<0.001)$ (Table 4$)$.

Table 4. Comparison of postoperative follow up data between mesh fixed and non-fixed group

\begin{tabular}{|l|c|c|c|}
\hline \multicolumn{1}{|c|}{ Variables } & $\begin{array}{c}\text { Mesh fixed } \\
\text { group }(\mathbf{n}=\mathbf{3 0})\end{array}$ & $\begin{array}{c}\text { Mesh non fixed } \\
\text { group }(\mathbf{n}=\mathbf{3 0})\end{array}$ & p-value \\
\hline $\begin{array}{l}\text { Length of } \\
\text { hospital stay } \\
\text { (days) }\end{array}$ & $1.32 \pm 0.45$ & $1.11 \pm 0.23$ & 0.026 \\
\hline $\begin{array}{l}\text { Return to } \\
\text { normal } \\
\text { activities } \\
\text { (days) }\end{array}$ & $9.45 \pm 3.22$ & $6.45 \pm 2.14$ & $<0.001$ \\
$\begin{array}{l}\text { Cost of } \\
\text { treatment } \\
\text { (Rs) }\end{array}$ & $30500.00 \pm$ \\
4500.00 & $12000.00 \pm$ & $<0.001$ \\
\hline
\end{tabular}

\section{Discussion}

The fixation of mesh in TEP comes at a cost of increased operative expenses and higher incidence of chronic pain or inguinodynia. It is also questionable if the mesh fixation is at all needed as the tissue incorporation within the mesh provides a better and permanent fixation of itself. With this background we evaluated the outcome in mesh fixation versus non-fixation patients with unilateral inguinal hernia with respect to various clinical parameters.

Patients in the mesh fixed group were significantly older than those in the non-fixed group $(45.8 \pm 13.74$ years and $55.47 \pm 16.74$ respectively; $\mathrm{p}=0.017$ ). All of the patients in both groups in our study were males. Garget, et al. ${ }^{12}$ found similar results.

In our study, on comparing pain intensity using VAS score in mesh fixed and non-fixed group. After 1, 6 and 24 hours of surgery, the mean VAS score was significantly low in non-fixed group $(\mathrm{p}=0.003, \mathrm{p}=0.033$ and $\mathrm{p}=0.047$ ) as compared to mesh fixed group. After 1 week and 3 months of surgery, the VAS score was almost equal in both the groups which showed statistically insignificant result $(\mathrm{p}=0.126, \mathrm{p}=0.183)$.

The pain score also varies with the function of time. In a study conducted by Buyukasik, et al..$^{13}$ in 100 patients, at time of discharge and in first month the VAS score was more in mesh fixed group ( $\mathrm{p}=0.034$ and 0.001 , respectively) while at 6 and 12 months there was no significant difference ( $\mathrm{p}=0.109$ and 0.158 respectively) 
when compared the mean pain score with mesh not fixed group. Similar results also emerged from an Indian study by Gangopadhyay, et al. ${ }^{14}$. They observed average pain score at various designated time intervals were significantly high in mesh fixed group compared with non-fixed group (Table 2).

On comparing pain symptoms in long term follow up among 313 patients, Lau, et al. ${ }^{10}$ concluded that chronic pain after TEP may vary from $9 \%$ to $22 \%$ with mesh fixation. Another study on 929 patients evaluating similar outcome parameter following failed to show any difference in pain score at 1 week after surgery did found significant difference in pain score at 1 month $^{15}$. A Pakistani study on 63 patients also concluded increased pain in the mesh fixed group $(4.7 \pm 0.683$ and in non-fixation group versus $4.1 \pm 0.860$ in fixed group; $\mathrm{p}<0.001)^{16}$.

However studies have also opined that the pain score was better only in early postoperative period while follow-up at 1, 3 and 6 months did not show any significant difference ${ }^{17}$.

Another prospective randomized controlled study was published from Egypt on 60 patients with the objective of comparing mesh fixation and non-fixation in terms of postoperative pain and recurrence rates following TEP. It showed significant reduction in postoperative pain, chronic groin pain and early return to work in nonfixation group ${ }^{18}$.

We found that fixation of mesh does not significantly adds to the time with use of tacker device ( $\mathrm{p}=0.258)$. Other studies have also found that the mean operating time was comparable in mesh fixed and non-fixed group ${ }^{12,13}$.

In our study, seroma was present in $2(6.7 \%)$ patients in mesh fixed group and $516.7 \%$ patients in non-fixed group. Seroma was high in non-fixed group but it was statistically insignificant $(\mathrm{p}=0.228)$. Urinary retention was present in $10(33.33 \%)$ patients in mesh fixed group and $3(10.0 \%)$ patients in non-fixed group. It was significantly high in mesh fixed group as compared to non-fixed group $(\mathrm{p}=0.0 .028)$. In an Indian study conducted by Garget, et al. ${ }^{19}, 194$ hernias in 104 patients were randomized to mesh no fixation or fixation groups. They found similar seroma formation rate among both the groups (mesh fixed 10.4\% versus mesh not fixed $15.4 \%, \mathrm{P}=0.56$ ). Buyukasiket, et al. ${ }^{13}$, studied among 100 patients, they observed urinary retention was present in 17 (34\%) patients in mesh fixed group and only $5(10.0 \%)$ patients in non-fixed group. It was significantly high in mesh fixed group $(\mathrm{p}=0.007)$ which was similar to the current study.
In our study, on comparing analgesic use between mesh fixed and non-fixed group, in first hour after surgery, the mean analgesic use in mesh fixed group was $1.42 \pm 0.62$ and in non-fixed group was $1.18 \pm 0.57$ which was comparable and statistically insignificant $(\mathrm{p}=0.124)$. In prior to discharge, the mean analgesic use in nonfixed group was significantly less as compared to mesh fixed group $(\mathrm{p}=0.003)$. Similar result was observed by Buyukasik, et al. ${ }^{13}$ where, they found significantly higher necessity to use narcotic analgesics in the fixation group prior to discharge $(\mathrm{p}=0.025)$.

In a study conducted by Wang, et al. ${ }^{20}$, among 76 patients were randomized into two groups: TEP with a non-fixed mesh technique $(n=38)$ versus TEP with mesh fixation $(n=38)$. They observed that the highest number of cases of analgesic use in post-operative patients were from mesh fixation group. The percentage of patients prescribed analgesics was $26.3 \%$, while analgesics were used in 1 patient in non-fixed group (2.6\%), showing statistically significant differences $(\mathrm{p}<0.05)$ similar to the present study.

In our study the mean length of hospital stay among the patients in the fixation group was $1.32 \pm 0.45$ days compared to $1.11 \pm 0.23$ days in not fixed group ( $\mathrm{p}=0.026$ ). Similar result was reported by Gangopadhyay, et al. ${ }^{14}$ and Garg, et al. ${ }^{12}$ in terms of significantly lower hospitalization duration in mesh not fixed group.

The mean time to return to normal activities in present study was $9.45 \pm 3.22$ days in mesh fixed group and $6.45 \pm 2.14$ days in non-fixed group, which showed in non-fixed group had early return to normal activities as compared to mesh fixed group $(\mathrm{p}<0.001)$. Similar result was reported by Garg, et al. ${ }^{12}$ where they found the mean time to return to normal activities was significantly less in no fixation of mesh group compared to mesh fixation group $(9.88 \pm 3.3$ versus $7.59 \pm 1.3$ days ; $\mathrm{p}<0.001)$.

In our study, the cost of treatment was $30500.00 \pm 4500.00$ rupees in mesh fixed group and in non-fixed group it was $12000.00 \pm 3800.00$ rupees which showed the cost of treatment was significantly low in non-fixed group as compared to mesh fixed group ( $\mathrm{p}<0.001)$. Comparative cost analysis done by Reddy, et al. ${ }^{21}$ observed that the mean cost of surgery significantly increased with use of fixation device. It infers that cost of surgery is significantly less in without fixation of mesh group compared to with mesh fixation group. Another study by Wang, et al. ${ }^{20}$ also found that the cost of surgery is significantly less in non-fixation of mesh group compared with mesh fixation group $(p<0.05)$. A meta-analysis of RCTs comparing staple fixation versus 
non-fixation in inguinal TEP repair concluded that tack mesh fixation is associated with increased operating costs, operating time and stay in hospital ${ }^{22}$.

The authors do admit that the study has limitations like small study population, single-centered research without female patients, post-operative follow-up duration is short for recurrence evaluation and above all patients with chronic and bilateral hernia have not been included in this study.

\section{Conclusion}

Fixing the mesh during TEP repair was associated with various postoperative complications, with no additional benefit. In conclusion, the results of this study indicate that laparoscopic repair of inguinal TEP hernia without mesh fixation is safe and feasible, with no increase short term recurrence rates. The technique also reduces the risk of postoperative complications, hospitalization expenses and hospital stay. For subgroup analyses more studies with larger sample sizes are needed.

\section{References}

1. Kumar S, Wilson RG, Nixon SJ, Macintyre IM. Chronic pain after laparoscopic and open mesh repair of groin hernia. Br. J. Surg. 2002; 89:1476-79. https://doi.org/10.1046/j.13652168.2002.02260.x. PMid:12390395.

2. Memon MA, Cooper NJ, Memon B, Memon MI, Abrams KR. Meta-analysis of randomized clinical trials comparing open and laparoscopic inguinal hernia repair. Br. J. Surg. 2003; 90:1479-92. https://doi.org/10.1002/bjs.4301. PMid: 14648725.

3. Heikkinen TJ, Haukipuro K, Koivukangas P, Hulkko A. A prospective randomized outcome and cost comparison of totally extraperitoneal endoscopic hernioplasty versus Lichtenstein hernia operation among employed patients. Surg. Laparosc. Endosc. 1998; 8:338-44. https://doi.org/10.1097/00019509199810000-00003. PMid: 9799140.

4. Liem MS, van der Graaf Y, van Steensel CJ, Boelhouwer RU, Clevers GJ, Meijer WS, Stassen LP, Vente JP, Weidema WF, Schrijvers AJ, van Vroonhoven TJ. Comparison of conventional anterior surgery and laparoscopic surgery for inguinal hernia repair. N. Engl. J. Med. 1997; 336:1541-47. https://doi. org/10.1056/NEJM199705293362201. PMid: 9164809.

5. Johansson B, Hallerback B, Glise H, Anesten B, Smedberg S, Roman J. Laparoscopic mesh versus open preperitoneal mesh versus conventional technique for inguinal hernia repair: A randomized multicenter trial (SCUR Hernia
Repair Study). Ann. Surg. 1999; 230:225-31. https://doi. org/10.1097/00000658-199908000-00013. PMid: 10450737, PMCid: PMC1420865.

6. Watkin D. Why does NICE not recommend laparoscopic herniorraphy? Patients must consider potential serious complications. BMJ. 2002; 325:39. https://doi.org/10.1136/ bmj.325.7359.339. PMid: 12169520, PMCid: PMC1123843.

7. Beattie GC, Kumar S, Nixon SJ. Laparoscopic total extraperitoneal hernia repair: Mesh fixation is unnecessary. J. Laparoendosc. Adv. Surg. Tech. A. 2000; 10:71-73. https://doi. org/10.1089/lap.2000.10.71. PMid: 10794209.

8. Schmedt CG, Sauerland S, Bittner R. Comparison of endoscopic procedures vs Lichtenstein and other open mesh techniques for inguinal hernia repair: A meta-analysis of randomized controlled trials. Surg. Endosc. 2005; 19:188-99. https://doi.org/10.1007/s00464-004-9126-0. PMid: 15578250.

9. Taylor CJ, Wilson T. Long-term results of laparoscopic totally extraperitoneal inguinal herniorrhaphy. ANZ J. Surg. 2005; 75:637-39. https://doi.org/10.1111/j.1445-2197.2005.03487.x. PMid: 16076322.

10. Lau H, Patil NG, Yuen WK, Lee F. Prevalence and severity of chronic groin pain after endoscopic totally extraperitoneal inguinal hernioplasty. Surg. Endosc. 2003; 17:1620-23. https:// doi.org/10.1007/s00464-002-8798-6. PMid: 12874688.

11. Hindmarsh AC, Cheong E, Lewis MP, Rhodes M. Attendance at a pain clinic with severe chronic pain after open and laparoscopic inguinal hernia repairs. Br. J. Surg. 2003; 90:1152-54. https://doi.org/10.1002/bjs.4213. PMid: 12945086.

12. Garg P, Rajgopal M, Vargese V, Ismail M. Laparoscopic total extraperitoneal inguinal hernia repair with nonfixation of mesh for 1,692 hernias. Surg. Endosc. 2009; 23(6):1241-45. https://doi.org/10.1007/s00464-008-0137-0. PMid: 18813990.

13. Buyukasik K, Ari A, Akce B, Tatar C, Segmen O, Bektas H. Comparison of mesh fixation and non-fixation in laparoscopic totally extraperitoneal inguinal hernia repair. Hernia. 2017; 21(4):543-48. https://doi.org/10.1007/s10029-017-15902. PMid: 28214943.

14. Gangopadhyay A, Ghosh B. To compare advantage of nonfixation versus fixation of mesh in laparoscopic Totally Extra Peritoneal (TEP) repair of inguinal hernias. Asian Journal of Medical Sciences. 2018; 9(4):35-40. https://doi.org/10.3126/ ajms.v9i4.19621.

15. Taylor C, Layani L, Liew V, Ghusn M, Crampton N and White $\mathrm{S}$. Laparoscopic inguinal hernia repair without mesh fixation, early results of a large randomized clinical trial. Surg. Endosc. 2008; 22:757-62. https://doi.org/10.1007/s00464-007-9510-7. PMid: 17885789.

16. Ayyaz M, Farooka MW, Toor AA, Malik AA, Khokhar HA, Khan A, et al. Mesh fixation vs. non-fixation in total extra peritoneal mesh hernioplasty. J. Pak. Med. Assoc. 2015; 65(3):270-72. 
17. Sağıroğlu J, Özdemir T, Atak T, Gök MA, Erdoğan KO, Eren $\mathrm{T}$, et al. Laparoscopic total extraperitoneal inguinal hernia repair without mesh fixation: report of early outcomes. South Clin. Ist Euras. 2016; 27(3):215-19. https://doi.org/10.14744/ scie.2017.64872.

18. Darwish AA and Hegab AA. Tack fixation versus nonfixation of mesh in laparoscopic transabdominal preperitoneal hernia repair. The Egyptian Journal of Surgery. 2016; 35:327-31. https://doi.org/10.4103/1110-1121.194729.

19. Garg P, Nair S, Shereef M, Thakur JD, Nain N, Menon GR, et al. Mesh fixation compared to non-fixation in total extra peritoneal inguinal hernia repair: A randomized controlled trial in a rural center in India. Surg. Endosc. 2011; 25(10):3300-06. https://doi.org/10.1007/s00464-011-1708-z. PMid: 21533969.
20. Licheng Wang, Xizun Jin, Haixia Wang, Xianping Zhou. Laparoscopic transabdominal preperitoneal procedure with and without mesh-fixation for inguinal hernia repairs. Int. J. Clin. Exp. Med. 2018; 11(8):8651-55.

21. Reddy RRS, Girish TU, Chandra BJS. A prospective comparative study of total extraperitoneal inguinal hernia repair: fixation versus without fixation of the mesh. Int. Surg. J. 2017; 4:166-69.

22. Tam KW, Liang HH, Chai CY. Outcomes of staple fixation of mesh versus nonfixation in laparoscopic total extraperitoneal inguinal repair: A meta-analysis of randomized controlled trials. World J. Surg. 2010; 34(12):3065-74. https://doi. org/10.1007/s00268-010-0760-5. PMid: 20714896. 